\title{
Impactos da população atingida pela estiagem no município de Taperoá, Paraíba
}

Nas regiões semiáridas, a vulnerabilidade das populações às variações climáticas constitui um grave problema. Os agricultores familiares são ainda mais vulneráveis, pois além de serem dependentes de recursos naturais, sofrem impactos na produção agrícola causados pela deficiência hídrica, de tal forma que não conseguem lidar com esses eventos, podendo ser uma situação que enfraquece a sua base de recursos e também a sustentabilidade do sistema. O município de Taperoá - PB (70 12' 23" Sul - 360 49' 25" Oeste), Estado da Paraíba (Brasil), está localizado na microrregião do Cariri Ocidental. Limita-se ao Norte, com Areia de Baraúna, Salgadinho e Assunção, Leste, com Santo André e São José dos Cordeiros, Sul, com São José dos Cordeiros e Livramento, Oeste, com Cacimbas e Passagem. Possui uma área de 644,155 Km² e população estimada em 15193 pessoas. Nos seus aspectos climáticos, a região está caracterizada por chuvas concentradas em um único período ( 3 a 5 meses), variando as médias anuais de 400 a 800, sendo nos últimos 10 anos as piores médias registradas por ano. 0 índice de vulnerabilidade à seca encontrado foi de $67,4 \%$, sendo considerada muito alta evidenciando o estado permanente de debilidade socioeconômica. Indica ainda, a inexistência de políticas e infraestrutura para a convivência com o semiárido. $O$ alto valor de vulnerabilidade à seca encontrado expressa os níveis críticos de exposição e fragilidade a desastres ambientais em que vive a população.

\section{Impacts of the population affected by the drought in the municipality of Taperoá, Paraíba}

In semiarid regions, the vulnerability of populations to climatic variations is a serious problem. Family farmers are even more vulnerable, as in addition to bein dependent on natural resources, they suffer impacts on agricultural production caused by water deficit, in such a way that they cannot deal with these events, which can be a situation that weakens their resource base and also the sustainability of the system. The municipality of Taperoá - PB (70 12' 23" South - 360 49' 25" West), State of Paraíba (Brazil), is located in the micro-region of Western Cariri. It is limited to the North, with Areia de Baraúna, Salgadinho and Assunção, East, with Santo André and São José dos Cordeiros, South, with São José dos Cordeiros and Livramento, West, with Cacimbas and Passagem. It has an area of $644,155 \mathrm{~km}^{2}$ and an estimated population of 15,193 people. In its climatic aspects, the region is characterized by rains concentrated in a single period ( 3 to 5 months), with annual averages ranging from 400 to 800 , with the worst averages recorded per year in the last 10 years. The drought vulnerability index found was $67.4 \%$, being considered very high, evidencing the permanent state of socioeconomic weakness. It also indicates the inexistence of policies and infrastructure fo living with the semiarid region. The high value of vulnerability to drought found expresses the critical levels of exposure and fragility to environmental disasters in which the population lives.

Keywords: Semiarid; Risk; Water Management.

Topic: Engenharia Agrícola

Reviewed anonymously in the process of blind peer.
Received: 02/04/2021

Approved: $27 / 04 / 2021$
Júlia Soares Pereira (iD

Universidade Federal de Campina Grande, Brasil

http://lattes.cnpq.br/8908354485683197

http://orcid.org/0000-0002-6495-1169

julia eng@hotmail.com

João Miguel de Moraes Neto (iD)

Universidade Federal de Campina Grande, Brasil

http://lattes.cnpq.br/3720844263112296

http://orcid.org/0000-0002-1299-6488

moraes.ninja@hotmail.com

Viviane Farias Silva (ib)

Universidade Federal de Campina Grande, Brasil

http://lattes.cnpq.br/5011520274887172

http://orcid.org/0000-0002-5891-0328

flordeformosur@hotmail.com

\section{Kalyne Sonale Arruda Brito (ic) \\ Universidade Federal do Amapá, Brasil \\ http://lattes.cnpq.br/4329763474442768 \\ http://orcid.org/0000-0001-9560-1164 \\ ine.brito@hotmail.com}

Wanessa Alves Martins (iD)

Universidade Federal de Campina Grande, Brasil

http://lattes.cnpq.br/4679230808516355

http://orcid.org/0000-0002-2108-2530

wanessamartins.eng@gmail.com
Referencing this:

PEREIRA, J. S.; MORAES NETO, J. M.; SILVA, V. F.; BRITO, K. S. A.; MARTINS, W. A.. Impactos da população atingida pela estiagem no município de Taperoá, Paraíba. Revista Ibero Americana de Ciências Ambientais, v.12, n.4, p.75-83, 2021. DOI:

http://doi.org/10.6008/CBPC2179-6858.2021.004.0008 


\section{INTRODUÇÃO}

No Brasil, a região semiárida do Nordeste é considerada uma das mais vulneráveis às variações climáticas devido a irregularidade das chuvas, deficiência hídrica, baixa capacidade de adaptação e pobreza da população (OBERMAIER, 2009). A ocorrência de secas - evento climático esperado nas terras semiáridas - faz da agricultura uma atividade naturalmente arriscada (RIBOT et al., 1996). Os agricultores familiares são ainda mais vulneráveis, pois além de serem dependentes de recursos naturais, sofrem impactos na produção agrícola causados pela deficiência hídrica, de tal forma que não conseguem lidar com esses eventos, podendo ser uma situação de vulnerabilidade que enfraquece a sua base de recursos e também a sustentabilidade do sistema (WEHBE et al., 2005).

Nas regiões semiáridas, a vulnerabilidade das populações às variações climáticas constitui um grave problema. Sendo assim, incertezas geradas pelo aquecimento global reforçam a urgência quanto a necessidade de buscar formas de enfrentar a variabilidade climática atual, através do fortalecimento da resiliência e da redução da vulnerabilidade, sendo definida por Turner et al. (2003a) como "o grau de probabilidade que um sistema, subsistema ou um componente do sistema tem de sofrer danos devido a exposição a um perigo, uma perturbação ou estresse".

O foco na sustentabilidade amplia e redireciona o estudo da vulnerabilidade e enfatiza os sistemas "homem-ambiente" - e a forma como a vulnerabilidade e a sustentabilidade baseadas nessa sinergia são afetadas por processos que operam em escalas espaço-temporais diferentes (TURNER et al., 2003b). Com este foco, a interação entre ambiente e sociedade é vista como um fator preponderante na influência e resposta de grupos sociais e seus meios de subsistência em situações de estresse (FRASER et al., 2003). Populações consideradas vulneráveis têm capacidade limitada de adaptação a perigos ambientais, em particular eventos extremos como secas e enchentes. Dessa forma, a vulnerabilidade é resultante da combinação entre fatores e condições sociais e riscos ambientais.

Wehbe et al. (2005) explicam que se uma determinada população agrícola é vulnerável a riscos climáticos não consegue lidar com eventos adversos, nem dispõe de mecanismos para isso, o resultado pode ser uma situação que compromete sua base de recursos e impede a sustentabilidade a médio e longo prazo. Para os autores, essa falta de capacidade adaptativa na agricultura pode indicar uma falta de sustentabilidade mais geral no sistema.

Diante do exposto, objetivou-se avaliar a vulnerabilidade à seca da população da zona rural no município de Taperoá-PB, com vistas a contribuir para o entendimento de questões sociais, econômicas e ambientais.

\section{METODOLOGIA}

O município de Taperoá - PB (70 12' 23" Sul - 360 49’ 25" Oeste), Estado da Paraíba (Brasil), está localizado na microrregião do Cariri Ocidental. Limita-se ao Norte, com Areia de Baraúna, Salgadinho e Assunção, Leste, com Santo André e São José dos Cordeiros, Sul, com São José dos Cordeiros e Livramento, 
Oeste, com Cacimbas e Passagem. Possui uma área de 644,155 Km² e população estimada em 15193 pessoas.

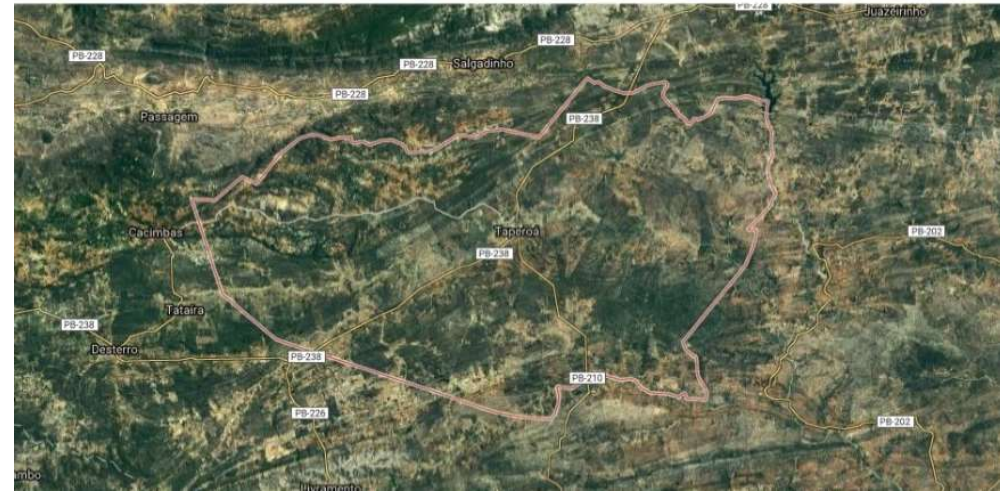

Figura 1: Município de Taperoá - PB e seus limites geográficos. Fonte: Mapasapp (2017).

De acordo com a classificação de Koppen, no município de Taperoá predomina o clima do tipo Bsh: semiárido quente, que abrange a área mais seca do Estado. Nos seus aspectos climáticos, a região está caracterizada por chuvas concentradas em um único período ( 3 a 5 meses), variando as médias anuais de 400 a $800 \mathrm{~mm}$. As temperaturas médias anuais são elevadas ( 23 a $27^{\circ} \mathrm{C}$ ). A umidade relativa anual é entre 50 e $60 \%$ e a evaporação média anual é de 2.000 mm/ano.

Encontra-se inserido nos domínios da bacia hidrográfica do rio Paraíba, sub-bacia do rio Taperoá, onde apresenta limitações pela alta evapotranspiração. As variações pluviométricas são as que efetivamente devem receber maior destaque, visto que delas dependem praticamente todas as atividades desenvolvidas no meio rural com influência direta na economia da região. O semiárido Paraibano é conhecido como uma região de baixa incidência de chuvas. Esse fato tem consequência socioambiental que justifica qualquer estudo com o intuito de ajudar a desenvolver políticas para a melhora nas condições locais.

Os principais corpos de acumulação são os açudes: Manoel Marcionilo, com capacidade máxima de 15.148.900 $\mathrm{m}^{3}$ de água; Lagoa do Meio (Municipal) com capacidade de $6.647 .875 \mathrm{~m}^{3}$ de água (ambos gerenciados pelo Estado) e as lagoas do Escuro, do Fernando, do Panati e da Canga. Nas figuras (2,3,4,5,6 e 7) observam-se a evolução do volume armazenado das águas do açude Manoel Marcionilo e Lagoa do Meio, ao qual demonstram os registros dos volumes anuais de aporte hídrico dos açudes.

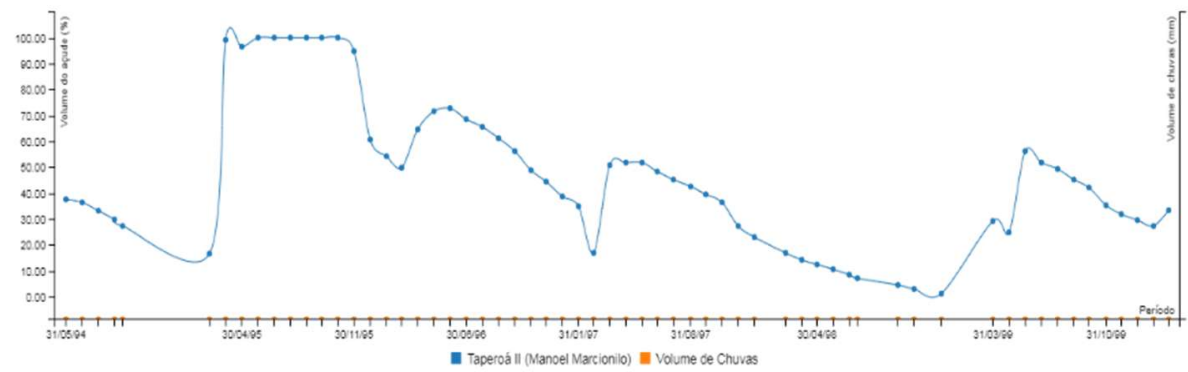

Figura 1: Variação do volume de água do açude Manoel Marcionilo - Taperoá/PB (1994-1999). 


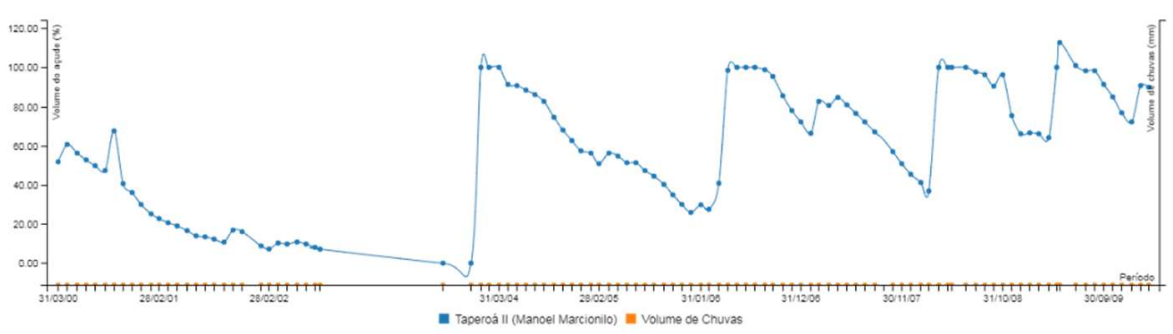

Figura 2: Variação do volume de água do açude Manoel Marcionilo - Taperoá/PB (2000-2009).

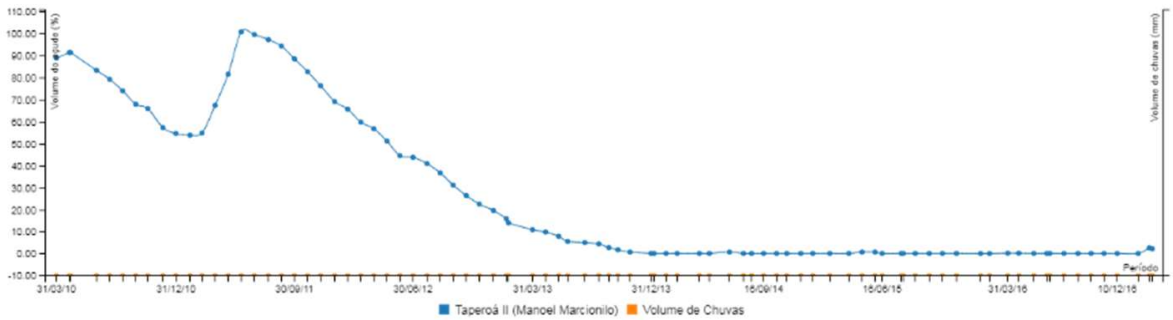

Figura 3: Variação do volume de água do açude Manoel Marcionilo - Taperoá/PB (2010-2016).

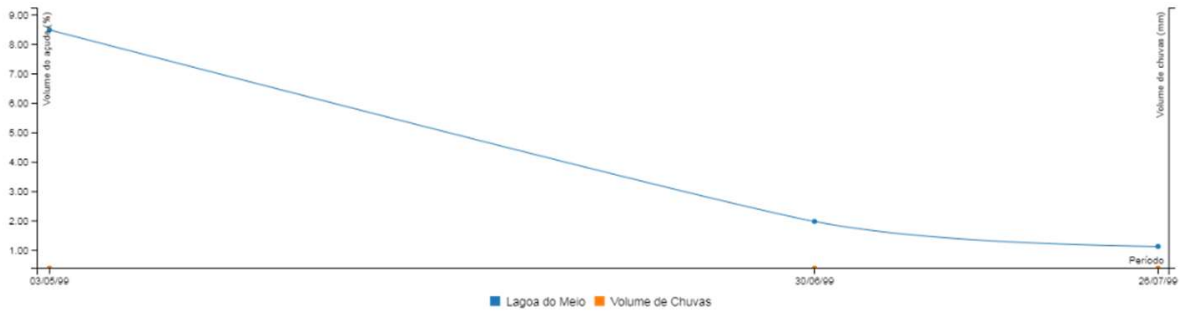

Figura 4: Variação do volume de água do açude Lagoa do Meio - Taperoá/PB (1999).

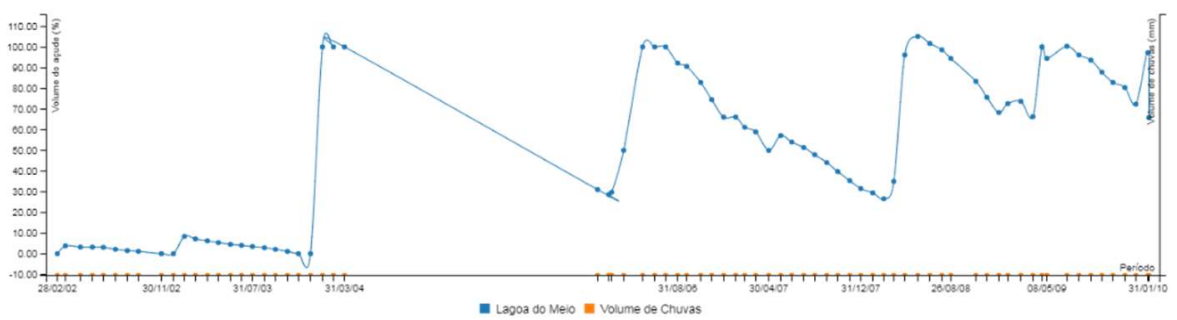

Figura 5: Variação do volume de água do açude Lagoa do Meio - Taperoá/PB (2002-2009).

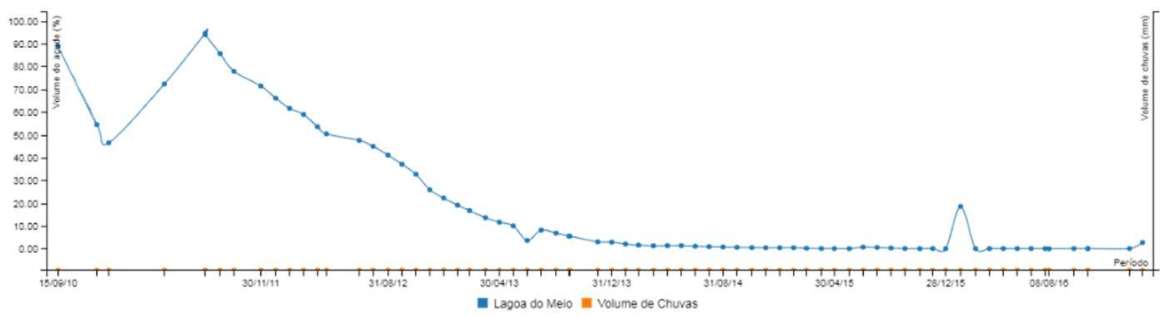

Figura 6: Variação do volume de água do açude Lagoa do Meio - Taperoá/PB (2010-2016).

A metodologia utilizada no diagnóstico socioeconômico e ambiental foi adaptado para o semiárido paraibano por um autor.

No diagnóstico socioeconômico foram considerados alguns fatores e suas variáveis: Fator vulnerabilidade social: demografia, habitação, consumo de alimentos, participação em organizações e salubridaderural; Fator vulnerabilidade econômica: produção vegetal, produção de animais de trabalho, verticalização, comercialização, crédito e rendimento; Fator vulnerabilidade tecnológica: tecnologia e máquinas; Fator vulnerabilidade ambiental ou à seca: recursos hídricos, produção, manejo de caatinga, exploração de espécies nativas, armazenamento, redução do rebanho, previsão de chuvas, educação e 
administração rural.

Os valores encontrados podem variar de zero (vulnerabilidade nula) até $100 \%$ (vulnerabilidade máxima) e são classificados em quatro classes (Tabela1).

Tabela 1: Classes de Vulnerabilidades.

\begin{tabular}{l|l|l|l}
\hline Baixa & Moderado & Alta & Muito alta \\
\hline $0-15$ & $16-30$ & $31-45$ & $>45$ \\
\hline
\end{tabular}

Através da seguinte equação: $V=a x+b$

V= vulnerabilidade variando de zero (nula) até 100 (máxima); $\mathrm{a}$ e $\mathrm{b}=$ constantes para cada fator; $\mathrm{x}=$ valor significativo encontrado.

O valor maior representa aumento de deterioração e o valor menor representa a menor deterioração. Para esta pesquisa iremos destacar a avaliação do fator vulnerabilidade à seca, em que se destaca: armazenamento de água, captação da água da chuva, fontes de abastecimento, aproveitamento de águas residuais e manejo da caatinga.

Os diagnósticos permitiram avaliar e identificar algumas características da sociedade que são inerentes à construção social da degradação das terras, através de questionários aplicados. Os questionários foram aplicados a $11 \%$ das famílias residentes na zona rural do município. Para calcular e gerar os gráficos foi utilizado o Microsoft Excel. Também foi realizado um trabalho de campo, que teve por finalidade fazer um reconhecimento geral da área, onde foram descritos os fatores ambientais (relevo, vegetação natural, erosão, declividade, uso atual das terras, aspectos sociais, econômicos e tecnológicos).

\section{RESULTADOS E DISCUSSÃO}

O índice de vulnerabilidade à seca encontrado foi de 67,4,8\% (Figura 8), uma vulnerabilidade muito alta e inaceitável, evidenciando a vulnerabilidade da população às secas e o estado permanente de debilidade socioeconômica. Indica ainda, a inexistência de políticas e infraestrutura para a convivência com o semiárido. A região paraibana é uma das áreas mais críticas em relação aos desastres (Seca) no Brasil. O despreparo para o enfrentamento de uma estiagem torna a população vulnerável, resultando em uma grande calamidade, acarretando graves problemas na produção agropecuária e repercutindo nas condições de vida e no trabalho da população (FARIAS et al., 2013).

Ao relacionar a vulnerabilidade com os riscos Veyret et al. (2007), direcionam o entendimento do conceito ao sugerir que ser vulnerável é estar fisicamente exposto a um perigo, apresentando certa fragilidade diante do evento e não ter condições ou os meios para enfrentar a crise, o que significaria a capacidade de um sistema complexo, como uma cidade, se restabelecer após uma situação de crise. Nesta concepção, quanto maior for a vulnerabilidade do sistema menor será sua capacidade de absorver a perturbação sofrida ou de se readaptar a nova situação.

Os resultados mostram que $58,7 \%$ das famílias fazem armazenamento de água em cisternas (Figura 9). Diante dos problemas de abastecimento que a população da região semiárida do país enfrenta a cada ano, no período de estiagem, faz-se necessário o uso de técnicas de aproveitamento de águas pluviais a fim 
de mitigar os efeitos da seca. Desse modo, existe uma grande diversidade de técnicas para captação e aproveitamento dessas águas, tais como a construção de cisternas para armazenar as águas das chuvas, que são coletadas dos telhados das casas, a construção de microbarragens, sistemas de infiltração, cacimbas de areia (cisternas no leito arenoso dos rios, poços rasos, etc.) (GNADLINGER, 2001).

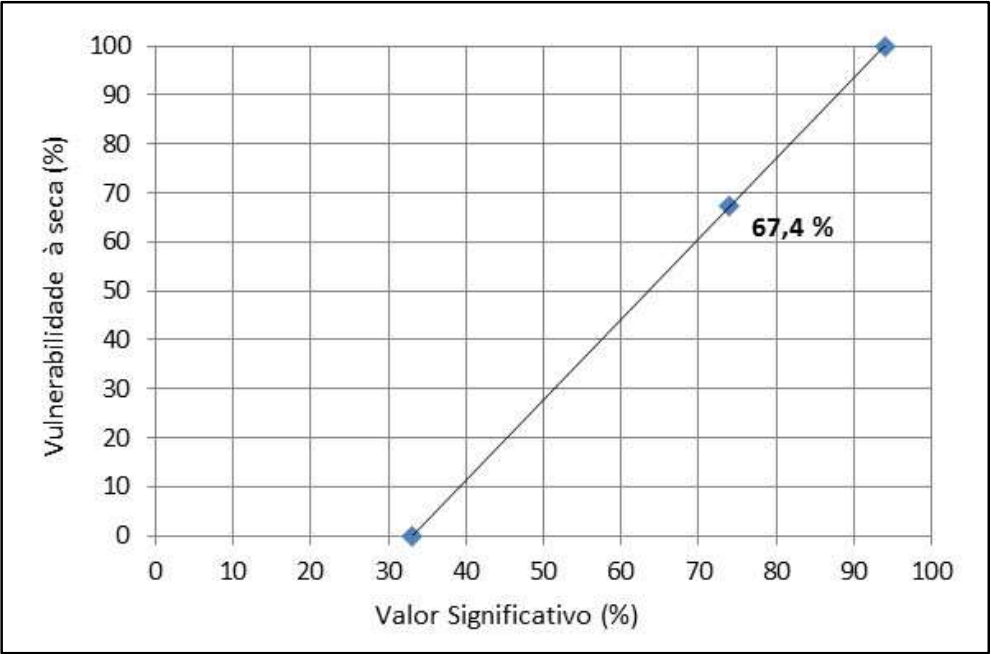

Figura 8: Vulnerabilidade à seca da população da zona rural no município de Taperoá - PB.

O desenvolvimento de ações de convivência com o semiárido na implantação de cisternas deve ser de caráter social, preservando os recursos naturais e ampliando de forma sustentável a produção familiar. Esse tipo de sistema possibilita o aumento da disponibilidade de água para beber, cozinhar, entre outros, garantindo o acesso descentralizado da água para o consumo humano, além de melhorar a qualidade de vida daqueles mais necessitados como as crianças, mulheres e idosos. Em cidades mais populosas e com um déficit no esgotamento pluvial, a execução de cisternas também pode auxiliar no controle de enchentes, evitando que a água seja lançada em maior demanda para galerias ou cursos hídricos, o que possivelmente diminuiria as inundações e alagamentos (MATIAS, 2001).
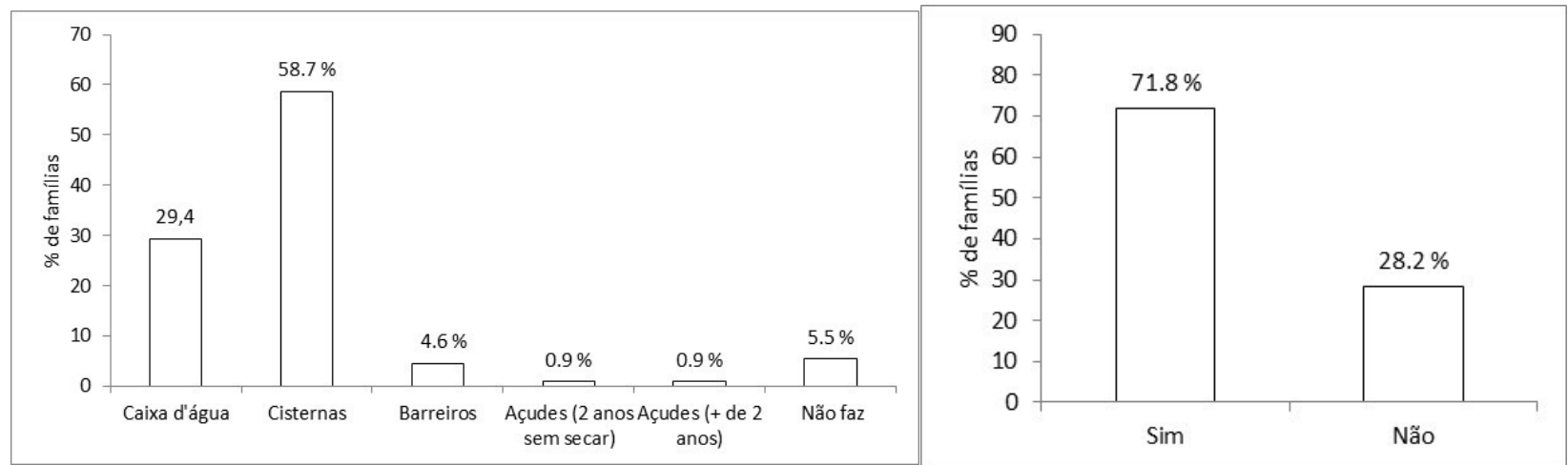

Figura 9: A) Formas de armazenamento das águas. B) Captação de água da chuva.

O abastecimento domiciliar é feito principalmente por carros pipa 42,5 \% (Figura 4), diariamente são encontrados animais fazendo o transporte de água dos açudes até as residências. Para $14,2 \%$ dos entrevistados, esse abastecimento é feito através de latas (Figura 10), onde essa água é transportada na maioria das vezes na cabeça e realizada por mulheres e crianças. Querino et al. (2017), ressalta a Operação Pipa como uma alternativa paliativa para amenizar a escassez hídrica para atender os municípios com a 
distribuição de água potável, não sendo garantia suficiente para atender a todos. O Exército realiza o cadastramento das famílias, estabelece a periodicidade de abastecimento das casas, local de colocação da água e as rotas com o percurso a ser realizado pelos caminhões pipa.

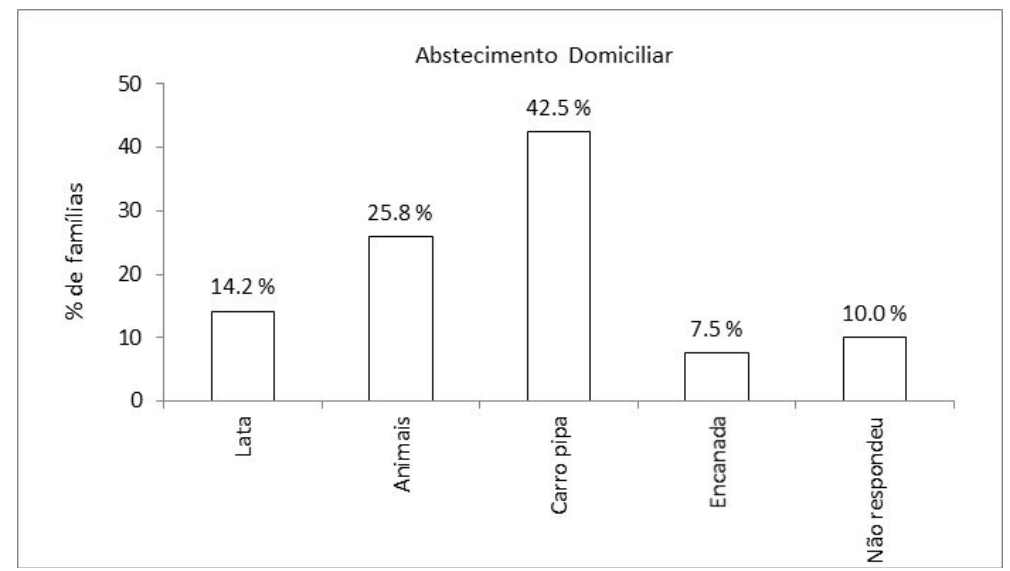

Figura 10: Formas de abastecimento domiciliar.

Com relação ao aproveitamento de águas residuais, 61,4\% não fazem esse reaproveitamento (Figura 11A). O reaproveitamento das águas residuárias é justificado, principalmente, em virtude da escassez hídrica, crescimento populacional e urbanização. $\mathrm{O}$ aproveitamento planejado de águas residuárias na agricultura além de favorecer a disponibilização de água para as culturas, também implica no controle da poluição d'água nos lençóis freáticos, na reciclagem de nutrientes e no aumento da produção agrícola (FARIAS et al., 2013). Segundo a Organização das Nações Unidas (ONU), no ano de 2016, cerca de 80\% das águas utilizadas são descartadas na natureza. Se fossem reaproveitadas, a necessidade pela água potável diminuiria, assim como seria reduzido também o volume de esgoto lançado nos rios, lagos, mares. Em pesquisa pelo coordenador da ASA no estado do Ceará algumas alternativas estão sendo realizadas para que não haja desperdício, como o chamado caminho das águas, onde é realizado cavar valas no terreno dos quintais das casas para que o líquido que escorre das pias e tanques alcance as raízes das fruteiras.

A agricultura é uma atividade que gera impactos ao meio ambiente, seja em grande ou pequena escala; isso dependerá das técnicas e práticas que forem utilizadas para cultivar a terra. As práticas agrícolas ineficientes que retiram a cobertura vegetal original do solo, deixando-o vulnerável aos processos erosivos. O desenvolvimento contínuo dessas práticas, de retirada de produtos sem a reposição de nutrientes, acarreta a perda da fertilidade da terra. Levando em consideração o tipo de solo da região, isso pode intensificar os processos de degradação do bioma. A agricultura irrigada, realizada sem levar em conta as características físicas da localidade, também pode acarretar sérios problemas, como salinização, erosão e lixiviação. 0 uso de máquinas também pode interferir na boa conservação do solo, pois poderá ocasionar processo de compactação, entre outros (SANTOS, 2009).

O bioma caatinga é companheiro e auxiliar na sobrevivência do homem no semiárido, produzindo alimentos, forragem para os rebanhos, produtos madeireiros e disponibilizando uma vital fonte energética, tanto para consumo doméstico quanto para atividades produtivas. No entanto, foi observado que $96,1 \%$ das famílias entrevistadas não fazem nenhum manejo da caatinga visando uma utilização sustentável (Figura 
11B), foi observado que a vegetação no local vem sendo explorada de forma predatória, é possível observar na área de estudo a evolução espaço-temporal do comportamento da cobertura vegetal, a principal causa dessa diminuição das classes de vegetação é a exploração desenvolvida sem planejamento. Um manejo sustentável da vegetação aumentaria e estabilizaria a produção de forragem para alimentar o rebanho de caprinos, ovinos, bovinos, aves, entre outros. É com o manejo adequado de espécies vegetais que o produtor pode garantir alimento de boa qualidade para o rebanho no período seco do ano e preservar as espécies vegetais.
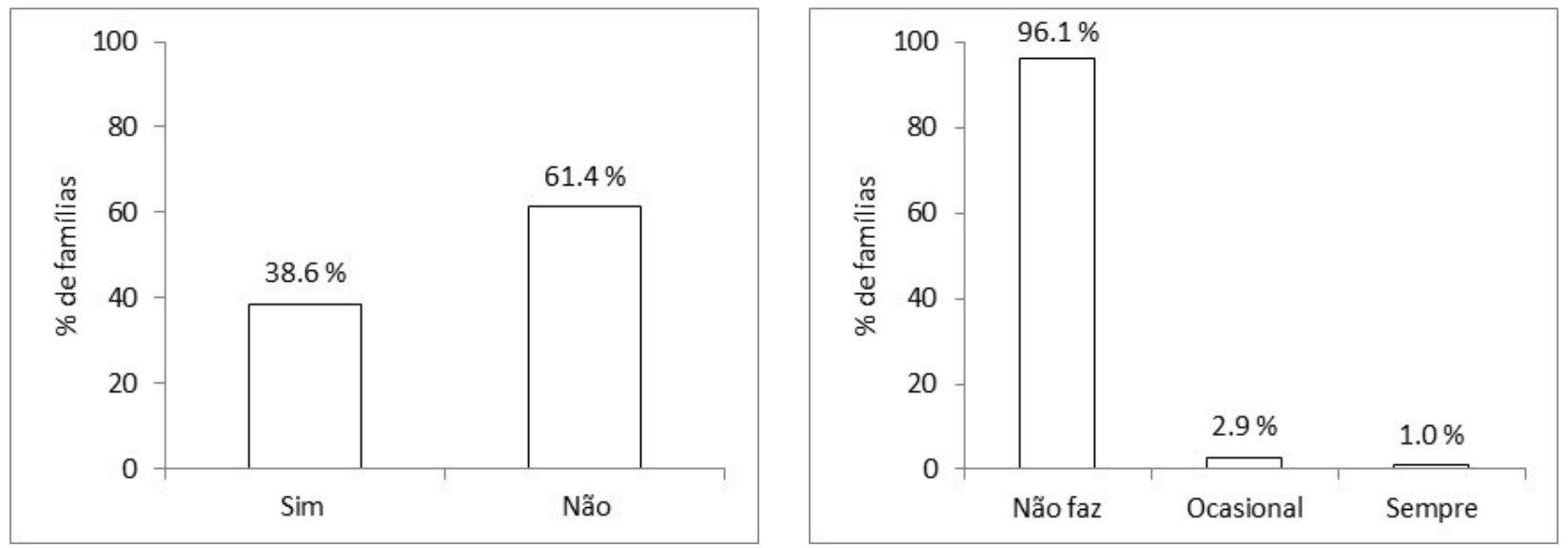

Figura 11: A) Aproveitamento de águas residuais. B) Manejo da caatinga.

\section{CONCLUSÕES}

A degradação está intimamente ligada à dinâmica das vulnerabilidades verificadas na região, sendo que a pobreza e a vulnerabilidade são condições que se reforçam mutuamente, seguido da deficiência nas políticas públicas, as condições climáticas desfavoráveis e solos de reduzida aptidão agrícola, principalmente quando estes recursos naturais são explorados por métodos insustentáveis do ponto de vista da sua preservação. $\mathrm{O}$ alto valor de vulnerabilidade à seca encontrado expressa os níveis críticos de exposição e fragilidade a desastres ambientais em que vive a população.

\section{REFERÊNCIAS}

FARIAS, A. A.; MORAES NETO, J. M.. Vulnerabilidade à seca de uma comunidade no município de Taperoá-PB. In: EXPEDIÇÃO DO SEMIÁRIDO, 2. Anais. UFCG, 2013.

FRASER, E. D. G.; MABEE, W.; SLAYMAKER, O.. Mutual vulnerability, mutual dependence: The reflexive relation between humam society and the environment. Global Environmental Change, v.13, p.137-144, 2003.

GNADLINGER, J.. A contribuição da captação de água de chuva para o desenvolvimento sustentável do semiárido brasileiro - uma abordagem focalizando o povo. In: SIMPÓSIO BRASILEIRO DE CAPTAÇÃO DE ÁGUA DE CHUVA NO SEMI-ÁRIDO, 3. Anais. 2001.

MATIAS, J. A. B.. Cisterna de placas pré-moldadas. In: SIMPÓSIO BRASILEIRO DE CAPTAÇÃO DE ÁGUA DE CHUVA NO SEMI-ÁRIDO, 3. Anais. Petrolina, 2001.

OBERMAIER, M.. Adaptation to climate change in Brazil: The pintadas pilot project and multiplication of best practice examples trough dissemination and communication networks. In: RIO 9 - WORLD CLIMATE \& ENERGY EVENT. Anais. Rio de Janeiro, 2009. p.185-190.

QUERINO, L. A. L.; SILVA, V. M. M. F.; SANTOS, C. A. C.. Atuação da operação carro-pipa em municípios do semiárido paraibano. In: WORKSHOP INTERNACIONAL SOBRE ÁGUA NO SEMIÁRIDO BRASILEIRO (WIASB), 2. Anais. 2015.

RIBOT, J. C.; NAJAM, A.; WATSON, G.. Climate variation, vulnerability and sustainable development in the semi-arid tropics. In: RIBOT, J. C.; MAGALHÃES, A. R.; PANAGIDES, S. S.. Climate Variability, Climate Change and Social Vulnerability in the Semi-Arid Tropics. Cambridge: Cambridge University Press, 1996. p.13-54.

SANTOS, L. L.. Quantificação do escoamento superficial e erosão do solo em regiões semiáridas. Revista Brasileira de Geografia Física, Recife, v.2, n.1, p.14-25, 2009. 
TURNER, B. L.; KASPERSON, R. E.; CHRISTENSEN, L.. A framework for vulnerability analysis in sustainability science. Proc Natl Acad Sci, Washington, v.100, n.14, p.8074-8079, 2003a. DOI: https://doi.org/10.1073/pnas.1231335100

TURNER, B. L.; MATSON, P. A.; MCCARTHY, J. J.; CORELL, R. W.; CHRISTENSEN, L. ECKLEY, N.; HOVELSRUD-BRODA, G. K.; KASPERSON, J. X.; KASPERSON, R. E.; LUERS, A.; MARTELLO, M. L.; MATHIESEN, S.; NAYLOR, R.; POLSKY, C.; PULSIPHER, A.; SCHILER, A.; SELIN, H.; TYLER, N.. Illustrating the coupled human-environment system for vulnerability analysis: Three case studies. Proc Natl Acad Sci, Washington, v.100, n.14, p.8080-8085, 2003b. DOI:

https://doi.org/10.1073/pnas.1231334100

VEYRET, Y.; RICHEMOND, N. M.. Definições e vulnerabilidades do risco. In: VEYRET, Y.. Os riscos: o homem como agressor e vítima do meio ambiente. São Paulo: Contexto, 2007. p.25-46.

WEHBE, M.; SEILER, R.; VINOCUR, M. G.; SANTOS, C.. Social Methods for Assessing Agricultural Producers: Vulnerability to Climate Variability and Change Based on the Notion of Sustainability. In: AIACC WORKING, 19. Anais. 2005. 